\title{
How To Get Your Manuscript Accepted For Publication: Insights From The Referees
}

\author{
Mario Reyes, University of Idaho, USA
}

\begin{abstract}
A survey of nineteen referees for the Journal of Applied Business Research (JABR hereafter) revealed four major reasons for accepting finance manuscripts submitted to the JABR: excellent writing and presentation, sound research design, clearly stated contribution, and a viable economic story or motivation. In this paper, I discuss these tips for accepting a manuscript for publication and conclude with a few insights as the finance editor for the JABR. Although the context discussed in this paper focuses on finance manuscripts, the insights shared by the referees are quite applicable to authors in other business disciplines because a well written paper with important research questions that are analyzed using sound econometric analysis or afforded a well-reasoned analysis deserves consideration for publication in any academic journal.
\end{abstract}

Keywords: publishing tips; writing tips; journal reviewing process; editorial process

\section{INTRODUCTION}<smiles>[C]1C=CCCC1</smiles>

everal authors have generously shared advice on academic writing and the publication process. For example, Cochrane (2005) offers valuable tips for young authors-from manuscript organization to effective writing to guidelines for empirical work. Frankfurter (2000) and Chance (2001) share their guidelines to publishing, including the selection of an appropriate outlet for one's paper and understanding a journal's preference for certain topics, research methods, and writing style. They then offer additional insights into the publication process - from formulating a submission strategy to responding to referees, and becoming a referee.

In this paper, I share additional insights into the manuscript review process ${ }^{1}$, discussing the major reasons offered by finance referees of the $J A B R$ for accepting a manuscript. A survey of the referees reveals four main reasons: excellent writing and presentation, sound research design, sufficient and clearly stated contribution, and a viable economic story or motivation. Although the discussion pertains to finance manuscripts submitted to the $J A B R$, the insights apply to manuscripts in other business disciplines as well because a well written paper with important research questions that are analyzed using sound research methods will merit consideration for publication in any academic journal. In the next section, I briefly describe the group of referees who shared their insights into the manuscript review process.

\section{THE REFEREES}

As the $J A B R$ finance editor, I have been fortunate to have developed a great relationship with many insightful and dependable referees. For this survey, however, I focus on nineteen referees who have reviewed several finance manuscripts for the $J A B R$ because of my familiarity with their styles, expectations, and approaches to the review process.

The referees range from junior finance researchers who have begun to achieve publishing success to established scholars. All have published in the mainstream journals in business, finance, and economics, such as Journal of Business, the Journal of Financial Economics, Journal of Finance, Journal of Banking and Finance, Journal of Financial Research, Journal of Financial and Quantitative Analysis, Journal of Behavioral Finance,

${ }^{1}$ This paper complements Fradkov (2003), who discusses the review process and then shares his experience as a referee. 
Journal of Financial Education, Financial Review, Review of Financial Economics, Journal of Economics and Finance, Journal of Political Economy, Journal of Applied Econometrics, and Theory and Decision. All of the referees are active reviewers for journals in business, economics, and finance. Several of the referees are journal editors, and many serve on various editorial review boards. These referees bring to the review process of the JABR manuscripts the insights they have gained from their own scholarship, and this, in turn, has greatly enhanced the quality of finance articles accepted for publication in the JABR.

\section{REFEREES' TOP FOUR REASONS FOR ACCEPTING A MANUSCRIPT}

In the survey of the referees, the highest ranked reason for accepting a manuscript was excellent writing and presentation. If writing reflects thinking, then good writing reflects good thinking; that is why well written papers are easy accept decisions. Excellent writing and presentation includes correct spelling, proper grammar and punctuation, precise writing, and logical rigor. A paper that is well written enables the reader to easily follow the direction, logic, and implications of the study. The referees note that clean presentation and crisp writing removes any doubts about other errors or short-cuts in the paper. On the other hand, poorly written papers with lack of attention to detail cause referees grief because they are unsure of what is going on in the paper.

The second most ranked reason for accepting a manuscript pertains to sound research design. This means that the hypotheses make sense both in terms of the research questions and in the statistical methods used to test each hypothesis. Moreover, the data and the statistical tools are appropriate for the research questions being studied. On the other hand, poorly designed studies or studies that employ inappropriate statistical techniques raise red flags because, as one referee writes, "modern computers allow the use of sophisticated statistical techniques at low cost and without understanding the nuances and limitations of the technique."

The third and fourth most stated reasons for accepting a manuscript in the JABR are closely related. The third reason refers to the clearly stated cogent contribution to the literature, and the fourth reason pertains to a "hook" or viable economic story. Strong manuscripts state the intended contribution(s) clearly, and this begins with a strong literature review. A referee writes: “... the main role of a literature review is to focus the reader on the precise contribution of the study to the overall existing literature," In other words, a strong literature review indicates that the authors have taken time to fully position their study within the relevant body of research. Hence, a paper that is positioned inadequately raises doubts in the referees' minds about value of the study. Insufficient positioning may also indicate a lack of familiarity with the literature, and this deficiency often results in poor development of hypothesis or poor choice of research question. A clearly stated contribution revolves around selecting a problem that has not been solved, a problem that is important, or a problem for which the solution advances the discipline.

Closely related to clearly stated contribution is an interesting "hook" (i.e., motivation) and a viable economic story. Strong manuscripts clearly describe at the beginning of the paper the research questions and why they are important. One referee writes that strong manuscripts promptly and clearly answer the question: "Why should the reader read this paper?" Solid manuscripts tell a viable economic story, thereby teaching the reader practical value that makes sense within the larger context of the existing literature. Weak manuscripts, on the other hand, tend to jump right into the statistical technique or the analytical results. A comment by one referee captures the sentiments of all referees: "Although it is important to get the statistical technique right, it is only a tool to tell a story. Telling the story is the most important part of the paper." Good manuscripts immediately hook the reader and tell a viable story. These manuscripts are easy "accept" decisions.

\section{AN EDITOR'S TAKE}

As the editor, I review the manuscripts before I decide whether or not to send them to the referees. Strong manuscripts - those that possess the qualities described in the previous section - are promptly sent to the referees. My alarms go off when: (1) references are outdated, (2) the data employed are old, and (3) the manuscript shows instances of sloppiness such as grammatical and typographical errors, missing references and/or inconsistency between the citations in the text and the reference because they raise concerns about what else is in error in the manuscript. I will reject the manuscript at that point so that I do not waste the referees' time. 
Sometimes, a manuscript is submitted with an accompanying explanation that the author's annual performance evaluation is coming up or that $\mathrm{s} / \mathrm{he}$ is going up for tenure and/or promotion and that the manuscript is essential in his/her endeavor. I understand the author's predicament. But my pet peeve is when the author immediately demands a decision on his/her manuscript. This is an easy decision for me because such demand shows (1) lack of professionalism, (2) that the author clearly does not understand the review process, (3) that the author is not familiar with the $J A B R$, and (4) that the author has little concern for making a contribution to the body of knowledge.

\section{SUMMARY AND CONCLUSION}

In this paper, I shared various insights for getting finance manuscripts accepted for publication in the $J A B R$. In a survey, referees revealed four major insights: excellent writing and presentation, sound research design, clearly stated sufficient contribution to the literature, and a "hook" and a viable economic story. Although the context discussed in this paper focuses on finance manuscripts, the insights shared by the referees are quite applicable to authors in other business disciplines because a well written paper dealing with important research questions that are analyzed using well designed research methods or afforded a well-reasoned analysis will merit consideration for publication in any academic journal.

\section{ACKNOWLEDGEMENT}

The author thanks Ron Clute for his encouragement and support in conducting this research.

\section{AUTHOR INFORMATION}

Mario Reyes is Associate Dean and Professor of Finance, College of Business and Economics, University of Idaho, Moscow, ID 83844-3161. Email: mreyes@uidaho.edu. Reyes is the Finance Editor for the Journal of Applied Business Research. The author thanks D'Wayne Hodgin, Ray Dacey, and Steve Shook for their comments and suggestions. The author also thanks the participants of the October 2010 International Business and Economic Research Conference in Las Vegas for their feedback on an earlier version. Of course, all remaining errors are mine.

\section{REFERENCES}

1. $\quad$ Chance, D. (2001), "Tips for Publishing in Finance Academic Journals." http://www.bus.lsu.edu/academics/finance/faculty/dchance/Research/PublishingTips.pdf

2. $\quad$ Cochrane, J.H. (2005), "Writing Tips for Ph.D. Students." University of Chicago manuscript (June 28). http://gsbwww.uchicago.edu/fac/john.cochrane/research/Papers.

3. $\quad$ Fradkov, A.L. (2003), "How to Publish a Good Article and To Reject a Bad One: Notes of a referee," Automation and Remote Control 64: 1643-1650.

4. Frankfurter, G.M. (2000), "The Young Finance Faculty's Guide to Publishing Inspired By and After (Rather Loosely) Benjamin Britten." International Review of Financial Analysis 9: 299-314. 


\section{NOTES}

